\title{
Independent Ethics Committee Opinion
}

National Cancer Institute

\section{Source}

National Cancer Institute. Independent Ethics Committee Opinion. NCI Thesaurus. Code C142580.

The judgment and/or the advice provided by an independent ethics committee. (ICH) 